\title{
Historia de la
}

revista Litoral: José

Bergamín, una

presencia constante

(1926-1984)*

History of the magazine Litoral: José Bergamin, a constant presence $(1926-1984)^{*}$

Luis Melero Mascareñas

* Este trabajo ha recibido financiación del Ministerio de Educación, Cultura y Deporte (MECD) para la Formación de Profesorado Universitario (FPU), Gobierno de España, y se ha realizado dentro el proyecto de investigación "Historia, ideología y texto en la poesía española de los siglos XX y XXI", PID2019-107687GB- 100 del Ministerio de Ciencia e Innovación, cuyo investigador principal es Juan José Lanz Rivera, y durante mi estancia como investigador visitante en la Universidad Complutense de Madrid, vinculado al grupo de investigación "Literatura, Heterodoxia y Marginación", Ref.:970747, cuyos directores son Santiago López-Ríos Moreno y Rebeca Sanmartín Bastida.

Recebido em: 13 de setembro de 2020

Aceito em: 17 de outubro de 2020

Graduado en Historia del arte (UMA). Doctorando en Estudios Avanzados en Humanidades (UMA). Actualmente es docente $e$ investigador en el Departamento de Filología Española, Italiana, Románica, Teoría de la Literatura y Literatura Comparada de la Universidad de Málaga, con una ayuda para la formación de profesorado universitario (FPU) del Ministerio de Ciencia, Innovación y Universidades, Gobierno de España. Contato: luismelero@uma.es Espanha 
PALABRAS CLAVE: José Bergamín; Litoral. Revista de Poesía, Arte y Pensamiento; Generación del 27; Poesía; Literatura contemporánea.

KEYWORDS: José Bergamín; Litoral. Poetry magazine, Art \& Thought; 27th Generation.; Poetry; Contemporary literature.
Resumen: José Bergamín estuvo en las páginas de Litoral en las horas primeras del comienzo de la revista, de la mano de Emilio Prados y Manuel Altolaquirre en el año 1926. La relación de José Bergamín con Litoral siempre fue estrecha, también desde su nuevo arranque en 1968, por iniciativa de José María Amado y Arniches. Junto a Rafael Alberti y Pablo Picasso, son tres presencias constantes en la historia de Litoral y podemos considerarlos como los mentores de la razón poética de José María Amado. Bergamín escribió y colaboró en la mayoría de los números de esta nueva época de Litoral -una relación que se prolongaría hasta la muerte del escritor, acaecida el 28 de asosto de 1983-, donde se le dedican, además, varios números monográficos, incluyendo títulos y epistolarios de valioso interés inéditos, que nos muestran a una de las personalidades más importantes de la literatura española contemporánea y del mundo intelectual del siglo XX.

Abstract: José Bergamín was in the pases of Litoral from the very beginning of the magazine, with Emilio Prados and Manuel Altolaguirre in 1926. José Bergamín's relationship with Litoral had always been close, also in his new start in 1968, thanks to the initiative of José María Amado y Arniches. Next to Rafael Alberti and Pablo Picasso, they were a constant presence in the history of Litoral and we can consider them as the mentors of the poetic reason of José María Amado. Bergamín wrote and collaborated in most of the issues of this new era of Litoral -a relationship that would last until the death of the writer, which took place on August 28, 1983-, where he was dedicated several monographic numbers, including unpublished titles and collection of letters of valuable interest, which bring us closer to the work of one of the most important personalities of the contemporary Spanish literature and the intellectual world of the twentieth century. 
José Bergamín estuvo en las páginas de Litoral en las horas primeras del comienzo de la revista, de la mano de Emilio Prados y Manuel Altolaguirre en el año 1926. Bergamín, un joven perteneciente a una de las mejores familias burguesas de Madrid, unido al afecto, a la palabra y a la amistad de los espíritus más prometedores de su generación, se encontró ante una de las revistas más significativas, podríamos decir «emblemática», que contó y cristalizó con los más valiosos creadores de la que iba a ser la nueva cultura española. En ese horizonte fundacional de la llamada «joven literatura» de los años veinte - después, generación del 27 -, parece haber acuerdo unánime entre historiadores y críticos en considerar que Litoral (Málaga, 1926-1929) fue, para la joven poesía y los jóvenes artistas plásticos del momento, un trampolín para las propuestas estéticas más vanguardistas.

La relación de José Bergamín con Litoral siempre fue estrecha, también desde su nuevo arranque en 1968, por iniciativa de José María Amado y Arniches, en un momento trascendente del mundo y de la historia y bajo la funesta sombra de la dictadura. José Bergamín, junto a Rafael Alberti y Pablo Picasso, son tres presencias constantes en la historia de Litoral y podemos considerarlos como los mentores de la razón poética de José María Amado. Amado conoció desde una edad muy temprana a Bergamín, el cual estaba casado con Rosario, hija del gran sainetista Carlos Arniches. Bergamín escribió y colaboró en la mayoría de los números de esta nueva época de Litoral, donde se le dedican, además, varios números monográficos. Una relación que se prolongaría hasta la muerte del escritor, acaecida el 28 de agosto de 1983. 
El número 1 de la revista aparece en noviembre de 1926. El 15 de mayo de 1926 Manuel Altolaguirre se lo anuncia a Juan Ramón Jiménez, en una carta donde aparecen los nombres de los primeros colaboradores, entre los que se encuentra José Bergamín (Altolaguirre, 2005, 37). Este primer número significó el signo inequívoco de la novedad, una lista extraordinaria y altamente reveladora de la «joven literatura». José Bergamín colaboró con un poema en prosa y de título gongorino, "Hija de la espuma", que dedica a la ciudad de Málaga y que tan bien encajaba con el espíritu fundador de la revista: "Ahora estoy atareadísimo con la preparación de una revista 'Litoral' dedicada al Mar solo y exclusivamente a EL. En ella entrarán poemas musicales, poesías, prosas dibujos... pero solo del Mar" (Prados, 2006, 39). Son aforismos de tono lírico que recuerdan la disposición ecléctica de su primer libro, El cohete y la estrella (Biblioteca de Índice, 1923), donde empieza con un poema narrativo en prosa aunque se trata de una colección de aforismos-, una forma literaria que muestra su temperamento como escritor, lo que Pedro Salinas llamó, en su reseña a La cabeza a pájaros (Ediciones del Árbol, 1934), "la ambición de la brevedad" (Salinas, 1934, 93-98)².

1 "Que, siendo Amor una deidad alada, / bien previno la hija de la espuma / a batallas de amor, campo de pluma" (Góngora, Soledades, 1613). En el Homenaje a Emilio y Manolo, números 13-14 (julio, 1970), aparece de nuevo en edición facsímil.

2 Véase «Ingenio de saeta: el aforista», en Dennis, N., José Bergamín. Introducción crítica (19201936) (Renacimiento, 2018), un capítulo imprescindible para conocer sus trabajos aforísticos y la medida de su percepción. 
En 1925 se publica en Madrid Tres escenas en ángulo recto (Biblioteca Índice, 1925) y, en febrero de 1927, en la Imprenta Sur de Málaga Caracteres ${ }^{3}$, como tercer suplemento de Litoral y único trabajo en prosa de la famosa colección ${ }^{4}$. En una carta fechada el 21 de diciembre de 1926, en la que Manuel Altolaguirre dice a Luis Cernuda lo mucho que le han gustado sus «Tres poesías» del libro inédito Perfil del aire (cuarto suplemento de Litoral, abril de 1927), le comunica que, además de haber editado ya $L a$ amante de Rafael Alberti (segundo suplemento de Litoral, noviembre de 1926), tenían en prensa Caracteres de Bergamín (Altolaguirre, 2005, 55-56). Tal vez lo más asombroso de los textos de José Bergamín es su «descarada vocación de poeta» (su ser más íntimo y verdadero), como diría Ramón Gaya, con la que, deliberadamente, traza una serie de perfiles de arquetipos humanos. Finalmente, el 10 de febrero de 1927, en una carta a Juan Guerrero,

3 Existen también dos reediciones en formato facsímil, una de ellas acompañada de un prólogo inédito de Bergamín (Madrid, Ediciones Turner, 1978) y otra en Litoral (números 109-110-111, 1982). Sobre su contenido, véanse especialmente la reseña -a partir de una reedición de Turner de 1981- de James Valender, en Revista de la Universidad de México (1983), donde dice que es uno de los libros más «atractivos» de Bergamín, y nos explica que permite ver una de las facetas menos conocidas del autor, como su trabajo de poeta en prosa, y, junto a ella, dos artículos de Nigel Dennis: El primero, "Caracterología bergaminiana», publicado en Nueva estafeta (febrero de 1979), y el comentario extenso dentro del capítulo "Trofeos de la sutileza: El estilista”, del libro José Bergamín, Introducción crítica (1920-1936) (Renacimiento, 2018).

4 Los suplementos publicados por Litoral entre 1926 y 1929 fueron: La amante (Rafael Alberti), Canciones (Federico García Lorca), Caracteres (José Bergamín), Perfil del aire (Luis Cernuda), Vuelta (Emilio Prados), La rosa de los vientos (José María Hinojosa), Versos y estampas (Josefina de la Torre), Ejemplo (Manuel Altolaguirre), La Toríada (Fernando Villalón), Ámbito (Vicente Aleixandre) y Jacinta la Pelirroja (José Moreno Villa). En un boletín de suscripción distribuido en Caracteres se anunció el proyecto de una segunda serie de suplementos, entre los que se encontraban El arte de birlibirloque, de José Bergamín, que fue publicado finalmente en Plutarco en 1930, y Jacinta la Pelirroja, de José Moreno Villa, el único que sería finalmente editado. 
Altolaguirre le escribe para comunicarle que: "Hoy hemos terminado la impresión del libro de José Bergamín, Caracteres. El mucho trabajo que hemos tenido nos impidió que le contestara antes" (Altolaguirre, 2005, 63). Dentro del proyecto editorial de la revista, Prados reitera a Sánchez Cuesta la importancia que se le concedió desde el principio a esta colección:

Claro está que nosotros no sabemos que no hay que pensar ni por un momento en que Litoral nos produzca un céntimo; pero eso no nos asusta, para eso tenemos puesta la Imprenta, con todas las molestias que nos acarrea, para que lo que ella produzca sirva para editar esta revista y sus suplementos, más interesantes que ella misma (Prados, 2006, 42).

En el número 3 de Litoral (marzo de 1927), aparecen "Tres composiciones viendo el lugar" ("El perro de Nietzsche", "La Nochebuena de Dostoïeswky" y "El purgatorio de Rimbaud"). Son textos que encajan en la prosa breve de aquellos, como la de otros poetas de su generación, caso de Luis Cernuda o Jorge Guillén. No podríamos llamarlos aforismos, pues son algo más extensos. Leyéndole en estos tres breves conjuntos, unidos a momentos claves de la vida de aquellos autores que dejaron una impresión duradera en él, vemos de qué manera ejerce una prosa corta, incisiva. Cuando Ramón Gaya señaló su «endiablada inteligencia», la "tentación del verso»en su prosa de los ańos veinte en un libro aparentemente aforístico como $E l$ cohete y la estrella (1923), podía considerarse que, al igual que en los textos publicados en Litoral:

No se trataba más que de un poeta. Era, pues, como un poeta... 'interroto', como un poeta que se interrumpe a sí mismo, que se detiene, que se detiene a pensar-pensar es siempre detenerse-, que se detiene a pensar en lo poético, 
no a decir en prosa lo poético de la realidad -eso es lo que hacía Ramón Gómez de la Serna-, sino a pensar y a decir en una especie de prosa que era como verso, lo poético de la poesía. (Gaya, 1973, 211-212).

En 1927, el grupo malagueño tomó partido de manera inequívoca en la celebración del III centenario de Góngora, con un número "que será cosa lenta, pues lo queremos hacer con todo cuidado" (Altolaguirre, 2005, 82), escribió entonces Manuel Altolaguirre a Juan Guerrero Ruiz. Un momento importante de encuentro y cohesión cultural, que vio en la publicación del número triple de Litoral (5, 6 y 7, octubre de 1927) su manifestación más lograda. En la relación de poetas que contribuyeron al homenaje que ofrece Gerardo Diego en su "Crónica del Centenario..." (en Lola, amiga y suplemente de Carmen, números 1 y 2, 1927-1928), añade entre paréntesis: "si se me olvida alguno, estará en el número de Litoral, 5, 6 y 7, declaración expresa de que tal número sería el acta de fidelidad gongorina de la generación” (Neira, 1978, 69-70).

José Bergamín estuvo presente en la mayoría de los actos organizados para el homenaje a Góngora ${ }^{5}$, aunque consideró siempre estas celebraciones como algo insignificante ${ }^{6}$. Con motivo del centenario gongorino se publica una décima de Bergamín en el homenaje de Litoral, parece ser que debido a la

5 Para los detalles de su actuación, véase la "Crónica del centenario de Góngora” de Gerardo Diego en Lola (amiga y suplemento de Carmen), números 1 y 2 (diciembre de 1927 y enero de 1928, respectivamente).

6 Véanse, por ejemplo, los artículos de Sábado gráfico, "Vista de pájaro" (número 931, abril de 1975) y "Pasemos la página" (número 1073, diciembre de 1977). Resulta interesante leer, cincuenta años después, el relato y la opinión de Bergamín sobre el homenaje a Góngora, cfr. Bergamín, J., entrevista de Jorge A. Marfil, "José Bergamín, una inteligencia inclasificable", El viejo Topo, Barcelona, n. 17, febrero 1978, 23-25. 
maña de Alberti y para sorpresa del propio autor (Dennis, 1978, 4). De la temprana obra poética de José Bergamín, esta décima de rasgos conceptistas ${ }^{7}$ es el único ejemplo publicado de su poesía de aquella época, antes de la guerra civil española, teniendo, por tanto, un gran interés histórico ${ }^{8}$. Dennis escribe que "se negaba a publicar sus versos porque no quería rivalizar con los demás poetas -terriblemente brillantes- de su generación. Es decir, que prefería mantener una identidad literaria peculiarmente suya" (Dennis, 1980, 208). Es interesante hacer notar el hecho de que Bergamín escribe a Jorge Guillén para que conozca la décima y la enjuicie, en una carta donde aparece además un "Soneto hermético", inédito hasta su publicación en un artículo de Nigel Dennis (Dennis, 1993, 64-73).

El número dedicado a Góngora supuso un gran esfuerzo económico para el grupo de Litoral, lo que trajo la consecuente crisis económica. Aquí acabaría la primera etapa de Litoral, produciéndose un silencio durante todo el año 1928 y parte de 1929, hasta que en mayo de ese mismo año, después de que Altolaguirre -muy a su pesar- se desvinculase de la imprenta, José María Hinojosa se incorporase a la dirección, tomando la revista un rumbo marcadamente surrealista. En el inicio de esta segunda etapa de Litoral, en el número 8 (mayo de 1929), se publican dos fragmentos, "Monóculo

7 Respecto a la utilización de la palabra conceptista usada para definir el estilo de la prosa de Bergamín, véase especialmente el análisis que hace Nigel Dennis en José Bergamín. Introducción critica (1920-1936) (Renacimiento, 2018), 168-182.

8 Esta décima se publicará nuevamente en el número doble especial de Litoral (27 y 28 de 1972). 
de Paul Valery" y "Los momentos dados", bajo el título El alma un hilo, acompańados de dibujos de Francisco Bores y de Joaquín Peinado.

Desde su nuevo arranque en 1968, iniciativa de José María Amado y Arniches, el «especialista en imposibles» según lo calificó Dionisio Ridruejo, Litoral lleva más de cincuenta años llegando a nuestras manos sin interrupción. Una publicación periódica que ofreció una mirada nueva y un enfoque distinto al margen de las directrices oficiales imperantes del momento (Ley 14/1966, 3310)9. Entre las personas a las que José María Amado consultó sobre la viabilidad de resucitar Litoral se encontraba José Bergamín. Las deudas específicas que tenían José María Amado y Litoral -ahora intitulada revista de la poesía y el pensamiento- con Bergamín serían cada vez más evidentes, no solo en su cita frecuente, sino también en su orientación poético-artística y político-filosófica, además de en el tono y el estilo de sus personalísimos artículos, que irá publicando como introducciones y puntos finales a cada uno de los números. Litoral significó, tal y como indica Antonio Jiménez Millán con relación a esta nueva época de Litoral: "no sólo un nombre vinculado al horizonte fundacional de la poesía de la generación del 27, sino también una referencia imprescindible en la cultura española de los últimos años de la dictadura y, por supuesto, de la transición" (Jiménez Millán, 2006, 183).

El número 1 de esta cuarta época (mayo 1968) se tituló Homenaje a una generación trascendente, la del 27, cuyos miembros estaban en su mayoría

9 Para Litoral supuso ser sancionada por orden de aquel penoso Tribunal de Orden Público, en varias ocasiones, por su contenido ya desde su primer número, Homenaje a una generación trascendente (mayo de 1968). 
exiliados o muertos a raíz de la Guerra Civil. Se publican el soneto núm. 1 de "Tres sonetos a Cristo Crucificado ante el mar"10 (1962) y "Yo soy de tu parecer" [poema], de Duendecitos y coplas ${ }^{11}$ (1963), que compuso, en su mayor parte, durante su estancia en Francia, en agosto de 1955. Unas coplillas ${ }^{12}$, escribe Bergamín en una carta a María Zambrano, "que me salen de más allá de mí mismo, como las otras del Cancionerillo, que llamo del Duende por eso. Del Duende y no del Ángel. (Andaluces los dos)" (Bergamín, 2004, 32). En el número 2 (junio-julio 1968), un arriesgado monográfico dedicado a Europa por el que la revista fue multada por haber incluido un artículo de J. M. Sanjuan ${ }^{13}$, aparece "Europa no habla griego, que habla gringo" [poema], de Rimas y sonetos rezagados $(1962)^{14}$, su primer libro de poemas. El número 3 (agosto-septiembre, 1968) es Desde Andalucía a Rafael Alberti, el primer monográfico homenaje íntegro a un autor desde una revista poética, y que comienza con la semblanza "El alegre", del libro Caracteres (tercer suplemento de Litoral, año 1927).

10 En Renuevos Cruz y Raya (1962), y que aparecieron inicialmente en Hora de España, Barcelona, n. ${ }^{\circ} \mathrm{XX}$, agosto de $1938,45-47$.

11 Duendecitos y coplas, en Renuevos de Cruz y Raya. Santiago de Chile - Madrid, Ediciones Cruz del Sur, 1963.

12 "Coplas a la andaluza romántico popular", escribe en una carta dirigida a Carmina Abril (Bergamín, 1985, 191).

13 Se trata del artículo titulado “¿De quién es el futuro?”, pp. 45-46, y su contenido suponía una ofensa al "debido respeto a las Instituciones y a las personas en la crítica de la acción política y administrativa” (Ley 14/1966, 3310).

14 Rimas y sonetos rezagados, en Renuevos de Cruz y Raya. Santiago de Chile - Madrid, Ediciones Cruz del Sur, 1962. 
Por los gustos personales de José María Amado, y posiblemente la influencia de Picasso y Bergamín, la tauromaquia está muy presente en esta nueva época. En el número 4 (octubre-noviembre, 1968), dedicado al toreo al que Bergamín dedicó muchas de sus páginas, se publica su soneto a Antonio Ordóńez, toreando en Arlés ${ }^{15}$. El número 5 (diciembre 1968 - enero, 1969) es un colofón de las fiestas navideñas. Por encima de las conmemoraciones mundanas y lejos del confesionalismo altisonante, el poema -once tercetos- que aparece en este número está al servicio de la misma causa poética y espiritual, una poética lección de amor. Su posición da a entender la honda sensibilidad religiosa de José Bergamín:

Dios le daba tiempo al tiempo

dándole una eternidad

al hombre en cada momento

Dándole Dios tiempo al tiempo

no le quitaba razón

de ser a lo que es eterno (Bergamín, 1968, 17-18)

El número 7 (abril-mayo, 1969), Los muros toman la palabra, analiza los acontecimientos del mayo francés. Una muestra de una manera de pensar, la de la juventud rebelde ante cualquier injusticia, donde tienen cabida también los siempre jóvenes Duendecillos y coplas de José Bergamín (17):

15 Ese mismo número incluye como separata una letrilla manuscrita de Rafael Alberti "A Don Luis de Góngora Lagartijo”, que escribió en el año 1927 para el centenario de Góngora y que no llegó a publicarse en la revista Papel de aleluyas que dirigía entonces Fernando Villalón, siendo pues, como se indica en el número de Litoral, rigurosamente inédita. 
Seguirás equivocado si te empeñas en seguir esperando lo pasado ${ }^{16}$.

Para el número 12 (febrero - marzo, 1970), Homenaje a Antonio Machado ${ }^{17}$, José Bergamín envía expresamente el soneto "Ecce España"18, haciendo, celebra José María Amado: "Un salto en su eterna pirueta y las piedras contra su propio tejado para enviarnos versos inéditos que nos llegan entre palmas alegres" (Amado, 1970, 54). Acaso expresó, de la forma más sintética, su postura hacia el tema de España tan presente en su obra.

Litoral dio también cabida a otras formas de expresión artística, como búsqueda de sus propias señas de identidad: a la música de Manuel de Falla (números 35-36) o a la pintura de Picasso (números 6, 22-23 y 221-212). En el número doble especial 17 y 18 (marzo, 1971), Homenaje al escultor Alberto, se publica una semblanza de José Bergamín similar a las de Caracteres, además de reproducirse un retrato suyo dibujado por el pintor Benjamín Palencia en el año 1924, y que apareció en la primera edición de su libro La cabeza a pájaros (1934).

16 En la contraportada.

17 Sobre la actitud de Bergamín hacia la figura de Machado, véase, entre otras referencias, "Antonio Machado 1939-1959", en El Nacional (Caracas), 22 de febrero de 1958.

18 La siguiente referencia que tenemos de este soneto es la de Poesías casi completas, Madrid, Alianza Editorial, 1980; también en el volumen Poesía-1, Madrid, Turner, 1983, 59. 
Entre las inquietudes de siempre de Bergamín, el toreo, singularmente simbólico, una cuestión palpitante entre filosofía, literatura y política ${ }^{19}$, como ya seńaláramos a propósito del número 4 (1968). Ronda y un torero (n. $21-22$, septiembre, 1971) es un homenaje a Antonio Ordóñez. En este número se publican varios poemas del autor. "A Diego del Gastor", el célebre guitarrista, uno de los mejores tocaores pa cantar que ha dado la historia del flamenco, dedica un hondo y elegante poema: "Música tan de verdad / que las estrellas se callan / para poderla escuchar”; también unas "Seguidillas toreras" y, lo más interesante, por su razón de inédito, la prosa "Desde mi burladero (Apostillas al toreo de Antonio Ordóńez)" enviada expresamente para este homenaje. Nos adelantamos algunos años hasta llegar al número 47-48, Ilustración y defensa del toreo (octubre, 1974), que incluye El arte de birlibirloque (Ediciones Plutarco, 1930), La estatua de Don Tancredo (Cruz y Raya, 1934, 3-47) y El mundo por montera (El Sol, 5 julio de 1936). Este número que Bergamín tituló Ilustración y defensa del toreo, y que comprende los tres ensayos anteriores, incluye un prólogo suyo para esta edición y un dibujo de Picasso $[1]^{20}$ que Bergamín entrega con su libro.

En el número doble especial 23-24 (diciembre, 1971 - enero, 1972), A los 90 años de Pablo Picasso, aparece un fragmento del artículo "Guernica"

19 Sobre el tema véase, entre otras referencias, los comentarios de Penalva en Tras las huellas de un fantasma. Madrid, Turner, 1985, 67-69 y 201-203.

20 En adelante, las referencias dentro del texto a las imágenes incluidas al final de este artículo irán numeradas consecutivamente entre corchetes. 
de Bergamín, publicado en Sábado Gráfico (10 diciembre, 1977) bajo la reproducción del célebre cuadro, y un poema autógrafo -la caligrafía es un material complementario a estos números, de valiosísimo interés para entender con garantías la tensión de la escritura contenida por los propios autores- titulado "La fantasma" [2]. Los números 25-26 (marzo, 1972), 27-28 (abril-mayo 1972) y 29-30 (junio-julio 1972) corresponden a las reproducciones facsimilares de los nueve primeros números de la primera época de Litoral. Unos ejemplares que, desde las reproducciones fragmentarias en el Homenaje a Emilio y Manolo (número 13-14, 1970), casi no existían entonces, sino en manos de contadas personas, resultando así de un extraordinario valor.

La presencia regular y destacada de la música en Litoral es un camino de ida y de vuelta con la poesía. Desde aquellas Seguidillas de la noche de San Juan de Gustavo Durán, aparecidas en 1926, Litoral ha contado con las colaboraciones de músicos de la categoría de Manuel de Falla: de él fue la música en el número triple extraordinario (números 5,6 y 7, 1927) en el homenaje a D. Luis de Góngora. De Cádiz a Granada, homenaje a Manuel de Falla, número doble especial 35-36 (enero-febrero, 1973), es un homenaje al célebre compositor. José Bergamín -como casi todos los escritores de la joven literatura espańola de los años 20-, siente una admiración enorme por la figura de Manuel de Falla, en la que, en su caso, a la dimensión artística se añade la espiritual ${ }^{21}$. Una doble deuda que, a pesar de las diferencias

21 Véase especialmente la edición de Nigel Dennis, El epistolario (1924-1935). José Bergamín/ Manuel de Falla. Valencia, Pre-textos, 1995, sobre la significación y desarrollo de las relaciones 
irreconciliables que los separarían, no dejará nunca de reconocer, como comprobamos en el ensayo que manda expresamente para este número de Litoral, al que añade una dedicatoria de su puño y letra, y que tan significativamente comienza con estas palabras:

Otras veces solía yo decir que había conocido personalmente a dos santos en mi vida: Jacques Maritain y Manuel de Falla. Ahora, en mi recuerdo, me parece que no he conocido más que a uno: Manuel de Falla. Al que dediqué -con su complacido consentimiento- uno de mis primeros libros: "Mangas y Capirotes", llamándole "maestro en la música y en la fe" (Bergamín, 1973, 26-28).

Litoral, siempre pendiente de una deuda pagada en páginas de poesía a José Bergamín, anunció en carta circular a todos los suscriptores en el número 35-36 (1973), la publicación de un libro de poesía inédito. Sería $L a$ claridad desierta ${ }^{22}$, fechado en París (1964-1968) ${ }^{23}$, con un importantísimo epílogo de Ramón Gaya - el mejor crítico de la obra de Bergamín según Nigel Dennis -, y que comprende los números extraordinarios 37-38 y 39-40 (marzo, abril, mayo y junio, 1973) ${ }^{24}$. Fuera de Madrid, le llega

entre músico y escritor.

22 Es Mallarmé quien inspira el título de La claridad desierta con este verso: “O nuits! ni la clarté déserte de ma lampe".

23 De ahí que cita Penalva a Aurora de Albornoz: "lo considera poesía del exilio" (Penalva, 1985, 260).

24 También en esta edición encontramos el prólogo que escribió Landsberg para la traducción alemana de La estatua de Don Tancredo (Cruz y Raya, 1934), traducido con el título de España eterna (Vita Nova, 1940), una estampa de Maruja Mallo, propiedad de José Bergamín y desaparecida al final de la guerra española, según indica a pie de imagen, un fragmento del prefacio a la edición francesa de El clavo ardiendo (París, Plon, 1972), hecha por Jean Claude Carrière y que, hasta este momento, no se había publicado el original en español, y el comentario de Xavier Villaurrutia a 
la noticia del homenaje a Vicente Aleixandre, que escribe a Litoral: "que otra nueva 'claridad desierta' nos pueble con nueva conciencia, con nuevo amor y con un nuevo estremecimiento" (Aleixandre, 1973, 35-37). Rafael Guillén manda para la ocasión, de su puño y letra, un poema de incuestionable valor, "El juego de Bergamín", y Rafael Alberti, omnipresente desde su exilio en Roma, firma una carta fechada el 10 de mayo con lenguaje limpio y de auténtica amistad: "Querido Bergamín: Ya no se estila / escribir en tercetos una carta / siguiendo el hilo que la rima enfila" (Alberti, 1973, 49).

Litoral publica por primera vez en España Roma, peligro para caminantes, número 43-44 (1974) ${ }^{25}$. Figura en esta edición un soneto autógrafo a Rafael Alberti escrito por José Bergamín para esta primera edición en España, fechado en Madrid, febrero de 1974. 50 números de Litoral, números 49-50 (1975), es la conmemoración -un hito-en la cronología, al llegar al número 50 del camino poético de Litoral. Recoge como novedad el prólogo firmado por José Bergamín en París, en 1969, titulado "Picasso, ahora y siempre" y que aparece en el libro Picasso laureatus (son oeuvre depuis 1945), publicado por La Bibliotèque des Arts, Lausanne (París, 1971).

Caballito del diablo (Buenos Aires, Losada, 1942) en la revista literaria El Hijo Pródigo (México, mayo, 1943), además de una biografía de Bergamín con bibliografía.

25 El libro está fechado así por el poeta: 1964-1967. La editorial mexicana Joaquín Mortiz lo editó por primera vez en julio de 1968 y, en 1972, el editor Mondadori lo publicó en Milán en una edición bilingüe con el título Roma, pericolo per i viandanti, cuya versión es de Vittorio Bodini, que murió antes de concluir su trabajo, por lo que esta edición está incompleta. 
El número triple 76-77-78 (1978) es un homenaje al inolvidable poeta César Vallejo y está dedicado al poeta español Juan Larrea, otra olvidada gran figura literaria. En este número se incluye el prólogo de José Bergamín a la segunda edición de Trilce de César Vallejo (Madrid, CIAP, 1930)26 y el artículo "Lenguaje de huego trágico", de gran interés y autógrafo Bergamín es para muchos el descubridor de César Vallejo en España -, enviado expresamente desde Madrid en mayo de 1978.

El siguiente está dedicado A Luis Cernuda, números 79-80-81(1978), una fecha doblemente simbólica para Litoral (se cumplían diez años de su renacer y acababa de celebrarse el cincuentenario de la generación del 27), en la que para celebrar ambas efemérides se convoca $^{27}$ a un grupo de intelectuales para que:

Señalen la personalidad literaria que consideren más completa por la amplitud de su expresión, de los miembros que aún viven de aquella generación y con mayor proyección sobre nuestra cultura dentro y fuera de España, y emitan su juicio en una especie de voto razonado en carta dirigida a la revista (Eds., 1978, s/p).

La convocatoria fue coordinada por Ángel Caffarena Such, en representación del primer Litoral, Francisco Giner de los Ríos, último superviviente en la dirección del Litoral mexicano y José María Amado, representando la continuidad en calidad de director del Litoral de 1968.

26 La primera edición, a cargo de Antenor Orrego, data de 1922 y fue su segundo libro, impreso en los Talleres Tipográficos de la Penitenciaría de Lima, autofinanciado y de un tiraje de tan sólo 200 ejemplares.

27 Dicha convocatoria se da a conocer por primera vez en el número 76-78 (1978). 
También, con voz y sin voto y como coordinadores de esta convocatoria, estaban Lorenzo Saval, como secretario para la recopilación de cartas y votos (sobrino nieto de Emilio Prados y el poeta más joven convocado, actual director de Litoral), y Félix Pastor Ridruejo, como notario del Ilustre Colegio de Madrid para dar constancia de ese recuento. De un total de 44 críticos consultados, 30 votaron por Bergamín. El resultado sirvió para mostrar la gran injusticia cometida con la obra de Bergamín, ignorada o minusvalorada (en especial su poesía). Fue una porción del reconocimiento público que evidentemente merecía.

La reproducción de las cartas de la lista de personalidades convocadas, en las que explicaban su decisión, son de un valioso interés como documentos literarios, «trascendental» como apuntó entonces José María Amado (Amado, 1978, 10). Fueron publicadas bajo el epígrafe "Resultado de una convocatoria" en una separata a la edición de Por debajo del sueño (Málaga, 1979), una antología poética que, como novedad, incluyó el entonces inédito Esperando la mano de nieve (Turner, 1982) ${ }^{28}$ y una nota bibliográfica de Gonzalo Penalva. En 1995 se reedita este volumen en Litoral / Ediciones UNESCO, con un liminar de Federico Mayor Zaragoza, una bibliografía ampliada y actualizada y un apartado final, "Bergamín en Litoral", a cargo de José Antonio Mesa Toré29.

28 Incluía también los títulos Rimas y sonetos rezagados (1962), Duendecitos y coplas (1963), La claridad desierta (1973), Del otoño y los mirlos (1975), Apartada orilla (1976) y Velado desvelo (1978).

29 En esta sección se puede consultar un índice detallado de todo lo publicado sobre Bergamín en Litoral. 
La amistad entre José Bergamín y Rafael Alberti es un hecho particularmente fecundo en lo que se refiere a la obra de ambos autores ${ }^{30}$. En enero de 1982 - un año antes de la muerte de Bergamín - aparece una curiosa correspondencia en verso (Roma-Madrid, mayo de 1971 - julio de 1972) entre José Bergamín y Rafael Alberti, en el número especial 109-110-111 (1982). Según los datos tomados de la introducción de José María Amado a este volumen, fue en la primavera de 1971, en una visita a La Gallarda, la casa de Aitana Alberti y Pepe Jiménez Rosado, muy próxima a la de José María Amado, donde surgió una conferencia con Roma -dice Amado-, buscando la voz de Rafael. Una conversación que, desde exilios diferentes, constituyó el punto de arranque de este intercambio epistolar.

Una correspondencia de la que Alberti llegó a decir en una carta a Aitana Alberti: "Pues esta tampoco podrá publicarse ahí: por ejemplo, en nuestro doblemente Amado Litoral" (Alberti [s/f] 1982, 20). Se trata de un documento literario muy interesante y poco conocido, que consta de 17 cartas: 10 de Alberti a Bergamín y 7 de Bergamín a Alberti. Como describe Antonio Jiménez Millán:

A través de una impecable construcción métrica que enlaza con el virtuosismo neobarroco de los años veinte, Alberti y Bergamín evocan amistades comunes, secuelas de la guerra y del exilio, detalles, a menudo sórdidos, de la situación española a principios de los setenta (Jiménez Millán, 2006, 198).

30 Véase especialmente el artículo ya citado de Nigel Dennis, "Rafael Alberti y José Bergamín: amistad y literatura”, Insula, número 379 (junio de 1978). 
Unos pasajes de amistad de «dos quis juntas como el siglo XX», recordó Rafael Alberti a la muerte de Bergamín:

Cartas de nostalgia, de tristeza y desconsuelo a veces, satíricas, divertidas, mordaces, pensando en esa España que ansiábamos y no llegaba nunca, perplejos ante la incógnita de la monarquía que el régimen franquista estaba preparando (Alberti, 1983, s/p)

\section{Nigel Dennis considera que ${ }^{31}$ :}

Más allá de las circunstancias en que fueron redactadas, las cartas postulan un principio fundamental que yace en el fondo de la obra de ambos escritores: que en última instancia la poesía se eleva por encima del tiempo y, contra viento y marea, afirma su radical permanencia. (Dennis, 1999, 203).

José Bergamín murió el 28 de agosto de 1983, a los 87 años. En los dos números triples dedicados a José María Hinojosa (números 133-134-135 y 135-136-137, ambos de 1983) -tal vez una de las figuras más injustamente olvidadas de aquel grupo de escritores jóvenes de la llamada generación del 27-, se incluía una separata titulada "Desde la intimidad de Litoral a José Bergamín”, un breve recordatorio de quien había sido el mentor ideológico de José María Amado en la nueva época de la revista.

31 Este es el único estudio sobre esta importante correspondencia en verso (Roma-Madrid, mayo de 1971-julio de 1972) entre José Bergamín y Rafael Alberti que hemos podido encontrar. También es interesante notar el hecho, hasta donde hemos podido indagar, de que sólo se ha publicado desde entonces en tres ocasiones más esta correspondencia, no habiéndose vuelto a editar en volumen independiente: en Alberti, Desprecio y maravilla (Barcelona, Seix Barral, 2002), donde en el prólogo menciona Pere Gimferrer, su aparición en el tercer tomo de la edición de Luis García Montero de esta misma obra (Madrid, Aguilar, 1988) y en las obras completas de Rafael Alberti, concretamente en el tomo IV, edición de José María Balcells (Barcelona, Seix Barral, 2005). 
El último tributo de Litoral a Bergamín, a una de las personalidades más importantes de la literatura contemporánea y al gran vacío en que quedaba inmersa la literatura espańola, fue la antología de los escritos periodísticos de José Bergamín, elaborada por Gonzalo Penalva. Una recopilación en tres volúmenes de una parte del quehacer periodístico de José Bergamín, publicados entre mayo y agosto de 1984 bajo el título El pensamiento de un esqueleto (3 vols., números 142-143-144, 145-146-147 y 148-149-150, 1984).

Según queremos indicar, a esta antología corresponden artículos de difícil acceso y poco conocidos, que ponen de relieve la dimensión múltiple de la obra de Bergamín. En el primer volumen hay que destacar el artículo titulado "La entereza de Unamuno", publicado en Le figaro Littéraire, número que fue requisado por la censura en España, y que se volvió a imprimir -de donde se transcribe- en el semanario uruguayo Marcha (Montevideo, 6 de noviembre de 1964, 13-14). En el segundo, se publican dos poemas de Francisco Giner de los Ríos ${ }^{32}$ dedicados a José Bergamín, fechados en Nerja, el 4 de septiembre de 1983. También hay que mencionar el poema "Volver", recogido en la sección número tres -dedicada al largo exilio de José Bergamín-, que fue escrito antes del primer regreso (fechado en París, 1957) y que, hasta entonces, no había sido recogido en ningún libro ni

32 Tras la guerra, se exilió en México, donde se casó con Maa Luisa Díez-Canedo, hija de Enrique Díez Canedo. Entró en contacto con Manuel Altolaguirre, Juan Rejano, José Moreno Villa y Emilio Prados, y allí, en 1944, reagrupado el núcleo del grupo malagueño, deciden fundar unos Cuadernos mensuales de poesía, pintura y música bajo el título Litoral. 
antología ${ }^{33}$, y ya en el tercer volumen, para concluir la antología, una parte de un texto que le entregó Bergamín a Gonzalo Penalva, como contestación a la pregunta que le había formulado acerca de qué era o qué significa para él la literatura, un texto hasta entonces inédito.

IMÁGENES REFERENCIADAS EN EL TEXTO:

Picasso

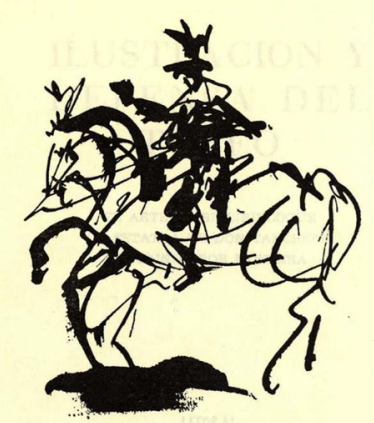

Figura 1 - Dibujo de Picasso que entrega Bergamín para el número 47-48 de Litoral, titulado llustración y defensa del toreo (octubre, 1974).

Fuente: Biblioteca Virtual de Prensa Histórica. Ministerio de Cultura y Deporte. Gobierno de España.

33 Fue publicado inicialmente en Índice y de ahí se reprodujo en Entregas de la Licorne (número 11, 1958, p. 59-60). 


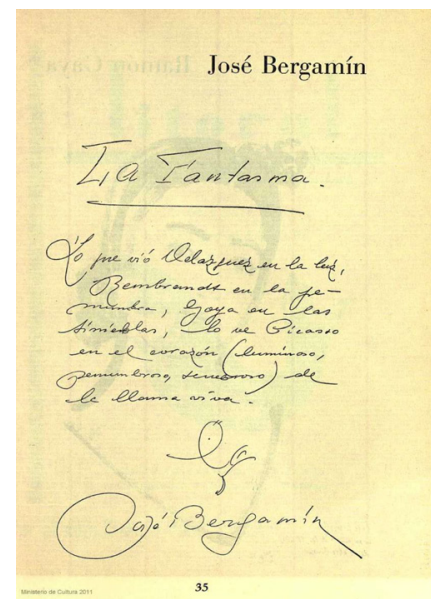

Figura 2 - Poema manuscrito y autógrafo de José Bergamín titulado "La fantasma", en Litoral, número doble especial 23-24 (diciembre, 1971 - enero, 1972), A los 90 años de Pablo Picasso.

Fuente: Biblioteca Virtual de Prensa Histórica. Ministerio de Cultura y Deporte. Gobierno de España.

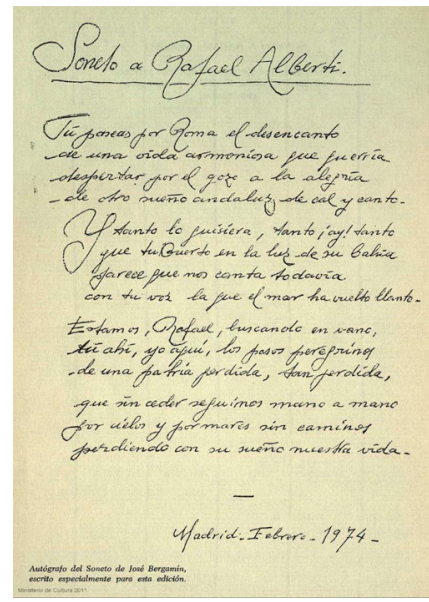

Figura 3 - "Soneto a Rafael Alberti", manuscrito y autósrafo de José Bergamín, escrito especialmente para Litoral, para la edición de Roma, peligro para caminantes, número 43-44 (1974).

Fuente: Biblioteca Virtual de Prensa Histórica. Ministerio de Cultura y Deporte. Gobierno de España. 


\section{REFERENCIAS BIBLIOGRÁFICAS}

Alberti, Rafael. [carta a José Bergamín. Roma, 10 de mayo]. In: Litoral. Revista de la Poesía y el Pensamiento. Málaga: n. ${ }^{\circ}$ 37-40, 1973, 49.

Alberti, Rafael. “José Bergamín. De X a X”. In: El País, 14 sept. 1983.

Aleixandre, Vicente. "Homenaje al poeta José Bergamín" [manuscrito con firma autógrafa]. In: Litoral. Revista de la Poesía y el Pensamiento. Málaga: n. o 37-40, 1973, 35-37.

Altolaguirre, Manuel. [carta manuscrita a Juan Ramón Jiménez. Málaga, 15 de mayo de 1926]. In: Valender, James (edit.). Manuel Altolaguirre. Epistolario (1925-1959). Madrid: Publicaciones de la Residencia de Estudiantes, $2005 \mathrm{a}, 37$.

Altolaguirre, Manuel. [carta manuscrita a Luis Cernuda. Málaga, 21 de diciembre de 1926]. In: Valender, James (edit.). Manuel Altolaguirre. Epistolario (19251959). Madrid: Publicaciones de la Residencia de Estudiantes, 2005b, 55-56.

Altolaguirre, Manuel. [carta mecanografiada a Juan Guerrero Ruiz, con firma autógrafa y el membrete: LITORAL. / San Lorenzo, 12. Málaga. 10 de febrero de 1927]. In: Valender, James (edit.). Manuel Altolaguirre. Epistolario (19251959). Madrid: Publicaciones de la Residencia de Estudiantes, 2005c, 63.

Altolaguirre, Manuel. [carta manuscrita a Juan Guerrero Ruiz en papel de luto, con el membrete: Manuel Altolaguirre. / San Lorenzo, 12. Málaga. Mayo-junio de 1927]. In: Valender, James (edit.). Manuel Altolaguirre. Epistolario (1925-1959). Madrid: Publicaciones de la Residencia de Estudiantes, 2005d, 82.

Amado, José María. "Punto final”. In: Litoral. Revista de la Poesía y el Pensamiento. Málaga: n. ${ }^{\circ} 12,1970,53-54$.

Amado, José María. "Acta de una convocatoria". In: Litoral. Revista de la Poesía y el Pensamiento. Málaga: n. ${ }^{\text {os }}$ 79-81, 1978, 9-12.

Bergamín, José. "En aquel tiempo, era el tiempo" [poema]. In: Litoral. Revista de la Poesía y el Pensamiento. Málaga: n. ${ }^{\circ}$ 5, enero de 1968, 17-18. 
Bergamín, José. "Manuel de Falla”. In: Litoral. Revista de la Poesía y el Pensamiento. Málaga: n. o 35-36, 1973, 26-28.

Bergamín, José. [Carta a Carmina Abril. París, 24 de agosto de 1955]. In: Penalva, Gonzalo. Tras las huellas de un fantasma. Aproximación a la vida y obra de José Bergamin. Madrid: Turner, 1985, 191.

Bergamín, José. [carta a María Zambrano. París, 22 de julio de 1957]. In: Dennis, Nigel (edit.). José Bergamín. Dolor y claridad de España (cartas a María Zambrano). Sevilla: Renacimiento [El Clavo Ardiendo, col.], 2004, 32.

Bergamín, José. [Carta a Carmina Abril. París, 24 de agosto de 1955]. In: Penalva, Gonzalo. Tras las huellas de un fantasma. Aproximación a la vida y obra de José Bergamin. Madrid: Turner, 1985, 191.

Amado, José María. "Punto final". In: Litoral. Revista de la Poesía y el Pensamiento. Málaga: n. ${ }^{\circ} 12,1970,53-54$.

Amado, José María. "Acta de una convocatoria". In: Litoral. Revista de la Poesía y el Pensamiento. Málaga: n. ${ }^{\circ 5}$ 79-81, 1978, 9-12.

Dennis, Nigel. "José Bergamín, poeta desconocido de la generación de 1927". In: Gordon, Alan M., y Rugg, Evelyn (Dir.). Actas del Congreso Internacional de Hispanistas. Toronto: Dept. of Spanish and Portuguese, University of Toronto, 22-26 de agosto de 1977, 207-210.

Dennis, Nigel. "Rafael Alberti y José Bergamín (amistad y literatura)”. In: Insula, n. 379 , junio de $1978,4$.

Dennis, Nigel. José Bergamín. Introducción crítica (1920-1936) [traducción de Teresa Moreno]. Sevilla: Renacimiento, 2018.

Dennis, Nigel. "Jorge Guillén y José Bergamín en 1927: fragmentos de un epistolario inédito". In: Revista de Occidente, n. ${ }^{\circ}$ 144, mayo de 1993, 64-73.

Dennis, Nigel. "X a X: la correspondencia en verso entre Rafael Alberti y José Bergamín”. In: Revista Canadiense de Estudios Hispánicos, vol. 24, n. ${ }^{\circ}$ 1, 1999 , 191-206. 
Dennis, Nigel. José Bergamín. Introducción crítica (1920-1936) [traducción de Teresa Moreno]. Sevilla: Renacimiento, 2018.

Gaya, Ramón. "Epílogo para un libro de José Bergamín”. In: Litoral. Revista de la Poesía y el Pensamiento. Málaga: n. ${ }^{\text {os } 37-40, ~ 1973, ~ 209-214 . ~}$

Jiménez Millán, Antonio. "Revista de Poesía, Arte y Pensamiento (notas sobre la nueva época de Litoral: 1968-2006). In: Neira, Julio (coord.). Litoral. Travesía de una revista (1926-2006). Málaga: Edita Centro Cultural Generación del 27. Diputación de Málaga, Consejería de Cultura de la Junta de Andalucía y Sociedad Estatal de Conmemoraciones Culturales, 2006, 182-223.

Neira, Julio. Litoral La revista de una generación. Santander: La Isla de los ratones, 1978.

Prados, Emilio. [carta a León Sánchez Cuesta. Málaga, julio de 1925]. In: Neira, Julio. "Litoral, la revista emblemática del 27". In: Neira, Julio (coord.). Litoral. Travesía de una revista (1926-2006). Málaga: Edita Centro Cultural Generación del 27. Diputación de Málaga, Consejería de Cultura de la Junta de Andalucía y Sociedad Estatal de Conmemoraciones Culturales, 2006a, 34-66.

Prados, Emilio. [carta a León Sánchez Cuesta. Málaga, enero de 1926]. In: Neira, Julio. "Litoral, la revista emblemática del 27". In: Neira, Julio (coord.). Litoral. Travesía de una revista (1926-2006). Málaga: Edita Centro Cultural Generación del 27. Diputación de Málaga, Consejería de Cultura de la Junta de Andalucía y Sociedad Estatal de Conmemoraciones Culturales, 2006b, 42.

Salinas, Pedro. "Los aforismos de José Bergamín”. In: Índice Literario, III, no 5 , mayo de 1934, 93-98. 